\title{
Analysis of Farmers' Perception and Decision on Soil Management in Relation to Climate Change
}

\author{
M. S. Hossen, M. A. H. Mozumder and M. N. Islam
}

Department of Environmental Science, Bangladesh Agricultural University, Mymensingh

\begin{abstract}
In Bangladesh, agriculture play an important role in sector of the economy and it is highly dependent on climate. The present study was conducted to assess farmer's perception on climate change and soil carbon sequestration (SCS) in the Ludhua village under Senbagh upazilla of Noakhali district during November 2012 to February 2013. The study consisted of 94 randomly selected farmers. It was observed that nearly about $77 \%$ respondent realized change in climate and $23 \%$ respondent found no variation in climate; among them $69.5 \%$ respondent claimed temperature is increasing. About $55.1 \%$ respondent believed man made activity responsible for extreme event (i.e. flood, cyclone, drought etc) while $38.5 \%$ respondent believed nature is the responsible for extreme event. Most of the respondent (94.7\%) found organic farming improves soil health. Crop residues are important source of soil organic matter which captures soil carbon by the formation of humus. About $86.1 \%$ respondent had concept about crop residue. Majority of the farmer (53.2\%) claimed that composting increase soil organic matter. Conservation agriculture like crop rotation, cropping pattern, conservation, tillage and stubble retention irrigation and fertilization are the main drivers for SCS. Although most of the (57.2\%) farmers had no idea about soil carbon and SCS but they followed various soils management practices for better crop yield (crop rotation $90.3 \%$, irrigation $98.96 \%$ and fertilization $96.8 \%$ ) which helps to increase soil organic carbon.
\end{abstract}

Key words: Climate change, Farmers perception, Soil carbon sequestration, Soil management

\section{Introduction}

Farmers' perceptions on climate change and variability are important in adaptation as they determine decisions in agricultural planning and management. Farmers can be influenced by peers' perceptions and values within their community in terms of climate change and variability (Maddison, 2006). Over the past decades, soil organic carbon has received increasing attention due to its potential capacity to play an important role in mitigating greenhouse gas (GHG) emissions (Wander and Nissen, 2004). In soil carbon management, increasing the soil $\mathrm{C}$ pool has been substituted with the term of soil carbon sequestration or SCS (Paustian et al., 2000). SCS defines the (long-term/permanent) removal of $\mathrm{CO}_{2}$ from the atmosphere into the soil. The benefits of soil organic matter for soil health, plant growth and production due to its fundamental role in the function and fertility of terrestrial ecosystems are well known. Sparling et al. (2006) proposed soil organic carbon management to have an environmental protection benefit of up to 40-70 times the productivity (yield) benefits. Climate change may have beneficial as well as detrimental consequences for agriculture. Climate change will be caused increasing of soil evaporation rates and increase the chances of severe droughts. Decomposition of soil SOC will more rapidly be occurred. Carbon sequestration in the agriculture sector refers to the capacity of agriculture lands and forests to remove carbon dioxide from the atmosphere. The amount of carbon stored in soil organic matter is influenced by the addition of carbon from dead plant material and carbon losses from respiration, the decomposition process and both natural and human disturbance of the soil. By employing farming practices that involve minimal disturbance of the soil and encourage carbon sequestration, farmers may be able to slow or even reverse the loss of carbon from their fields. The world's soils are the largest terrestrial reservoir of carbon. A sizable part of the damaging extra load of greenhouse gases in the atmosphere today comes from soil carbon released when we switched from traditional farming to intensive grain growing. Land use change such as converting pasture to woodland, using minimum tillage on cropland, or excluding livestock from pasture increases the amount of carbon sequestered in the soil. The present study dealt with awareness level of people in relation to climate change and soil carbon sequestration. The study also revealed the different impacts perceived by the people due to changes in climate and management regarding SCS.

\section{Study area}

\section{Methodology}

The study was conducted in Ludhua village under Senbagh upazilla (23 0' 56" North, $91^{\circ} 13^{\prime} 24^{\prime \prime}$ East) of Noakhali district a South-eastern part of Bangladesh. Senbagh upazilla of Noakhali district was selected purposively where high yielding rice varieties, vegetables and other crops are grown. In total Ninety four adult farmers identified as head of households were individually interviewed. Heads of household were considered as we hypothesized that he/she was the one to make decision about agricultural management practices and that his knowledge, perception etc were to be taken into account above all. 


\section{Instrument for collection of data}

A questionnaire schedule was prepared for collection of data from the respondents keeping the objectives of the study in mind. Both open and closed forms of questions were included in the interview schedule. The questionnaire was prepared in English and the questionnaire was pretested before preparing the final version of questionnaire for collecting the data for the study. The pretest was helpful in identifying faulty questions and statements. Necessary additions, deletions, modifications and adjustments were made in the interview schedule on the basis of experience gained from the pretest.

Farmer survey on perception of climate change, soil carbon sequestration and soil management

Farmers were asked closed and open-ended questions about farm activities, farmer climate knowledge and perceived climate change. To make a connection with farmer perception, farmers were asked questions about their age, level of education, marital status and number of children. Farmer main activities (agriculture, husbandry, commerce etc.) were also sought with an emphasis on crop types, water system (rainfed or irrigated), type of cultivar used, cropped land area per crop and right of land use (heritage, purchase, etc.) Farmers were asked to name the differences between the past climate and today's according to climate variables (rainfall pattern, temperature, extreme events). For instance, we asked if the rainfall onset / cessation was now early, late or unchanged compared to past climate; if the number of rainfall events or dry spells have decreased, increased or stay unchanged; if temperature, the number of hot /cool days in years have decreased, increased, or stay unchanged, etc. Open-ended questions were also asked to farmers to mention any other indicators of climate change in their environment. Impacts on agriculture were assessed by asking whether growing period, sowing and harvesting time, yield changes for climate change. To access soil management strategies, farmers were asked to list their strategies from the best to the least to adapt to climate change and to explain why they think they were worth doing. After that we asked the farmer closed-ended questions whether he/she knows the soil fertility management

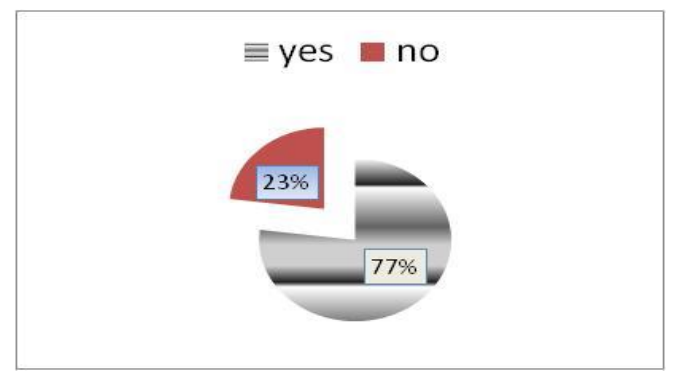

Fig. 1. Farmers' perceived climate change practices inorganic and organic fertilizer, cover crop, crop residues, tillage and why they do those practices.

\section{Data processing and analysis}

Data collected was subjected to descriptive analysis of simple proportions using the SPSS Version 12 statistics software. The main tools of analysis were descriptive statistics including frequency distribution for all variables. Uniformity between respondents in the different communities was determined using twoway Chi-square $(\chi 2)$ test of homogeneity analysis (Gomez and Gomez, 1984)

\section{Results and discussion}

\section{Farmer's perception on climate change}

Most of the respondents (77\%) have positively observed that climate change occurred and only $23 \%$ did not realize about climate change (Fig. 1). In case of annual temperature, most of the respondent $(69.5 \%)$ found temperature increased, $20.9 \%$ respondent found decreased and $9.6 \%$ did not found any change (Table 1). Due to temperature change, day-night temperature variation was occurred. About $46.8 \%$ respondent claimed small variation in daynight temperature where as $26.6 \%$ noticed moderate variation, $19.1 \%$ got huge variation and $7.4 \%$ found no variation at day night temperature. In case of annual precipitation $41.5 \%$ respondent replied that rainfall had not evenly distributed, $48.86 \%$ respondent replied due to uneven distribution of rainfall caused heavy rainfall at season and rest of the 9.64\% respondent claimed that distribution of rainfall evenly occurred (Table 1). Among them $52.1 \%$ found rainy season starts later, $29.8 \%$ found rainy season starts earlier, $8.5 \%$ found rainy season starts right on time and $9.6 \%$ had not any idea when rainy season start. Due to climate change natural disaster occurred frequently in this area, 66\% flood occurred, drought occurred $18.1 \%$, cyclone occurred $10.6 \%$ and other catastrophe strikes $6.6 \%$ (table 4.4). $55.1 \%$ respondent obtained this extreme event caused by manmade activity, $38.5 \%$ respondent believes this extreme event caused naturally and $6.4 \%$ had given other opinion (Fig. 2).

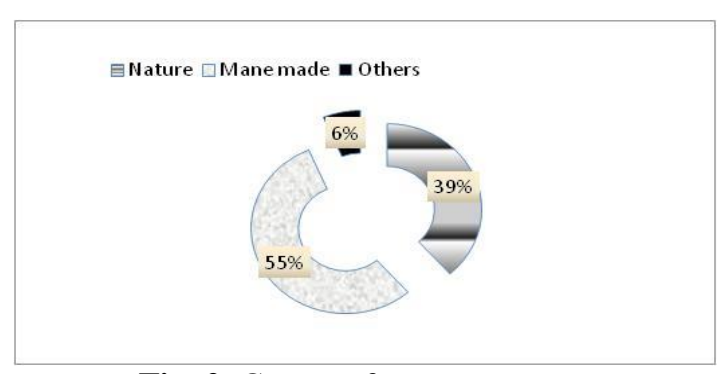

Fig. 2. Causes of extreme events 
Table 1. Distribution of respondents according to various factor of climate change

\begin{tabular}{|l|l|c|c|}
\hline \multicolumn{1}{|c|}{ Category } & Frequency & Percent \\
\hline \multirow{4}{*}{ Temperature } & Increasing & 65 & 69.5 \\
\cline { 2 - 4 } & Decreasing & 20 & 20.9 \\
\cline { 2 - 4 } & No idea & 9 & 9.6 \\
\hline \multirow{4}{*}{$\begin{array}{l}\text { Variation in day } \\
\text { night temperature }\end{array}$} & Found small variation & 44 & 46.8 \\
\cline { 2 - 4 } & Moderate variation & 25 & 26.6 \\
\cline { 2 - 4 } & Huge variation & 18 & 19.1 \\
\cline { 2 - 4 } & No variation & 7 & 7.4 \\
\hline \multirow{4}{*}{ Rainy season start } & Early starts & 28 & 29.8 \\
\cline { 2 - 4 } & Lately starts & 49 & 52.1 \\
\cline { 2 - 4 } & Starts at right time & 8 & 8.5 \\
\cline { 2 - 4 } & No idea & 9 & 9.6 \\
\hline \multirow{3}{*}{ Distribution of } & Not evenly distributed & 39 & 41.5 \\
\cline { 2 - 4 } & Evenly distributed & 09 & 09.64 \\
\cline { 2 - 4 } & Heavy rainfall at season & 46 & 48.86 \\
\hline \multirow{3}{*}{ Extreme event } & Flood & 62 & 66 \\
\cline { 2 - 4 } & Cyclone & 10 & 10.6 \\
\cline { 2 - 4 } & Drought & 17 & 5.1 \\
\cline { 2 - 4 } & Other & 5 & 5.3 \\
\hline
\end{tabular}

\section{Impacts of climate change on agriculture}

Most of the respondent (38.25\%) obtained growing period had been broader while $29.8 \%$ respondent observed growing period had been shorter, $19.1 \%$ respondent observed growing period remain at the same time and $12.85 \%$ respondent had no idea about growing period (Table 2). In case of sowing date most of the respondent $(45 \%)$ obtained sowing date had been later while $35.1 \%$ respondent found sowing date had been earlier, $18.8 \%$ respondent found sowing date remain at the same time and $1.1 \%$ respondent had no idea about sowing date( Table 2). Most of the respondent found harvest date had been later $(45.7 \%)$ while $31.9 \%$ respondent got harvest date had been earlier, $19.1 \%$ respondent found harvest date remain at the same time and 3.2\% respondent had no idea about harvest date( Table 2). Farmers were asked the impact of climate change caused any variation on agricultural production. $94.7 \%$ respondent found changes of yield occurred, only $2.1 \%$ respondent obtained changes of yield not occurred and 3.2\% respondent had no idea about yield variation (Table 2). Among the respondent $73.1 \%$ obtained negative effect, $23.7 \%$ obtained positive effect and 3.2\% respondent found same yield (Table 2).

Table 2. Impact of climate change on agriculture

\begin{tabular}{|c|c|c|c|}
\hline \multicolumn{2}{|r|}{ Category } & Frequency & Percent \\
\hline \multirow[t]{4}{*}{ Growing period } & Shorter & 28 & 29.8 \\
\hline & Broader & 36 & 38.25 \\
\hline & Same time & 18 & 19.1 \\
\hline & No idea & 12 & 12.85 \\
\hline \multirow[t]{4}{*}{ Sowing date } & Earlier & 33 & 35.1 \\
\hline & Later & 42 & 45 \\
\hline & At the same time & 18 & 18.8 \\
\hline & No idea & 1 & 1.1 \\
\hline \multirow[t]{4}{*}{ Harvest date } & Earlier & 30 & 31.9 \\
\hline & Later & 43 & 45.7 \\
\hline & At the same time & 18 & 19.1 \\
\hline & No idea & 3 & 3.2 \\
\hline \multirow[t]{3}{*}{ Changes of yield } & Yes & 89 & 94.7 \\
\hline & No & 2 & 2.1 \\
\hline & No idea & 3 & 3.2 \\
\hline \multirow{3}{*}{$\begin{array}{c}\text { Effect of changes } \\
\text { yield }\end{array}$} & Positive benefit & 22 & 23.7 \\
\hline & Negative effect & 69 & 73.1 \\
\hline & Same yield & 3 & 3.2 \\
\hline
\end{tabular}




\section{Soil management in relation to climate change mitigation}

Most of the respondent (91.5\%) followed tillage operation, $7.4 \%$ had no idea about tillage operation and 1.1 had not done any tillage operation on their land. From them most of the respondent done tillage operation at their land for good yield $(90.4 \%)$. Only $2.1 \%$ and $1.1 \%$ respondent done tillage operation for improving soil health and for increasing microbial activity respectively (Fig 3). By employing organic farming practices that involve minimal disturbance of the soil and encourage carbon sequestration (EPA 2008).

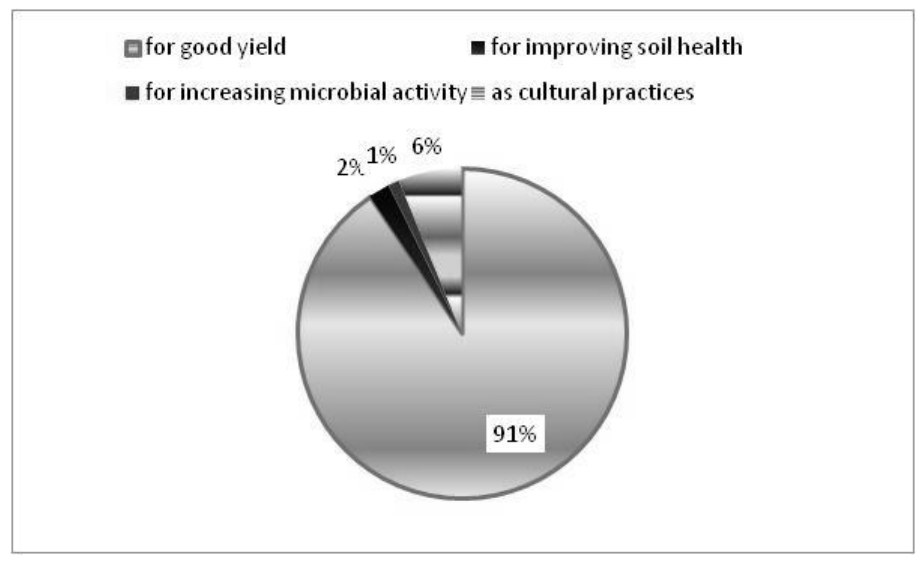

Fig. 3. Distribution of respondents according to reason of tillage operation

Crop rotation is an important for improving soil health, destroying certain pest infestation etc. Most of the respondent $90.3 \%$ knows about cropping pattern and rest $9.7 \%$ had not known about cropping pattern. Among them $42 \%$ respondent followed cropping pattern for improving soil health, $31 \%$ followed cropping pattern for profit, $21 \%$ respondent followed cropping pattern for destroying certain pest infestation and rest of the $6 \%$ followed crop rotation for other objective( Fig 4). A recent study by Luo et al. (2010) reviewed conservation agricultural practices (such as rotation cropping, conservation tillage and stubble retention and irrigation/fertilization) and found that increasing the crop frequency and perenniality and a combination of stubble retention and conservation tillage where the main drivers for SOC accumulation.

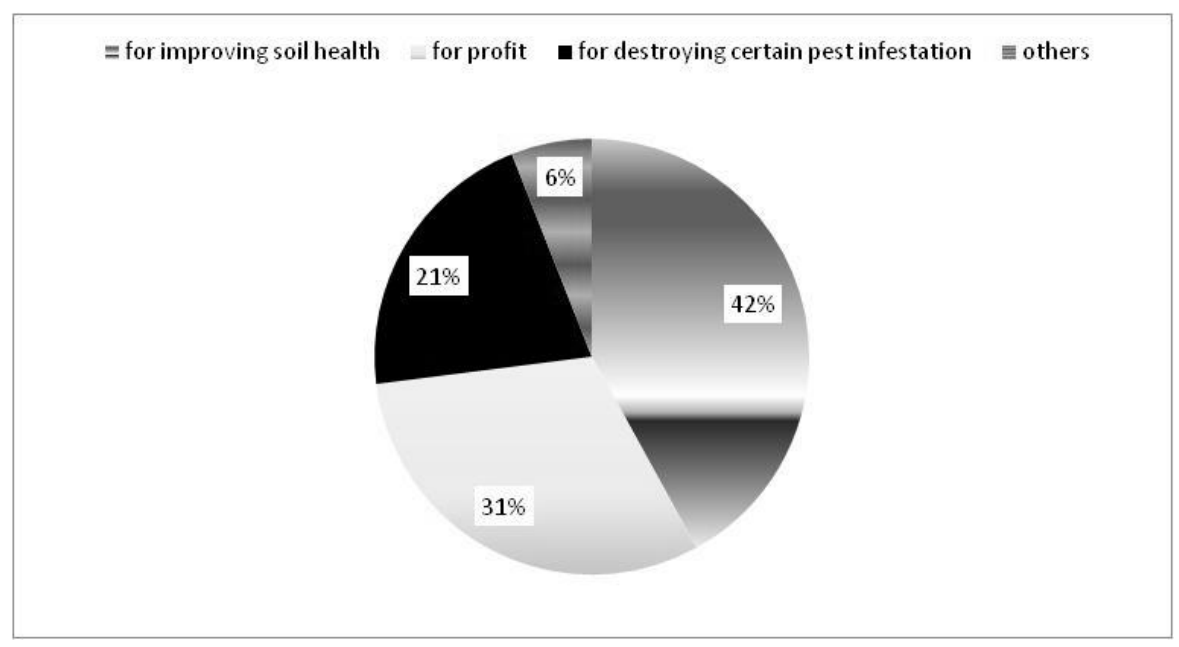

Fig 4: Distribution of respondents for reason of crop rotation 
Table 3. Purpose of cultivation cover crops

\begin{tabular}{|l|c|c|}
\hline Purpose of cultivation of cover crops & Frequency & Percent \\
\hline For improving soil health & 30 & 31.9 \\
For extra income & 16 & 17.0 \\
To preserve moisture & 33 & 35.1 \\
Conventionally & 15 & 16.0 \\
Total & 94 & 100.0 \\
\hline
\end{tabular}

Cover crops referred to as carbon sinks because they can store large amount of carbon on their vegetation. About $63.2 \%$ respondent grown cover sometimes, $26.5 \%$ respondent grown cover crops regularly and $10.5 \%$ did not grown cover crops. Among them $35.1 \%$ grown cover crops to preserve soil moisture, $31.9 \%$ grown cover crops for improving soil health, $16 \%$ grown cover crops for extra income and rest of the $16 \%$ grown cover crops conventionally (Table 3 ). Recent reports have investigated the potential of organic agriculture to reduce greenhouse gas emissions (Rodale Institute, 2008). Organic systems of production increase soil organic matter levels through the use of composted animal manures and cover crops.

Table 4. Distribution of respondents according to reason of fertilizer use

\begin{tabular}{|c|c|c|}
\hline Reason of fertilizer use & Frequency & Percent \\
\hline Improving soil health & 1 & 1.1 \\
Increasing yield & 74 & 78.7 \\
For more profit & 19 & 20.2 \\
Total & 94 & 100.0 \\
\hline
\end{tabular}

Balance fertilization is indispensible to avoid crop yield decline on cultivated land and to supplement nutrient loss from the soil. Majority (96.8\%) respondent applied fertilizer and rest $3.2 \%$ did not used fertilizer. They applied fertilizer increasing yield (69.2\%), for more profit $20.2 \%$ and $10.6 \%$ use fertilizer improving soil health (Table 4). Among the respondent $39.4 \%$ used inorganic fertilizer, $35.1 \%$ used both organic and inorganic fertilizer, $25.56 \%$ used organic fertilizer. Zhou et al. (2010) stated that not cost but yield as important factors for farmers decisions on fertilizer use.

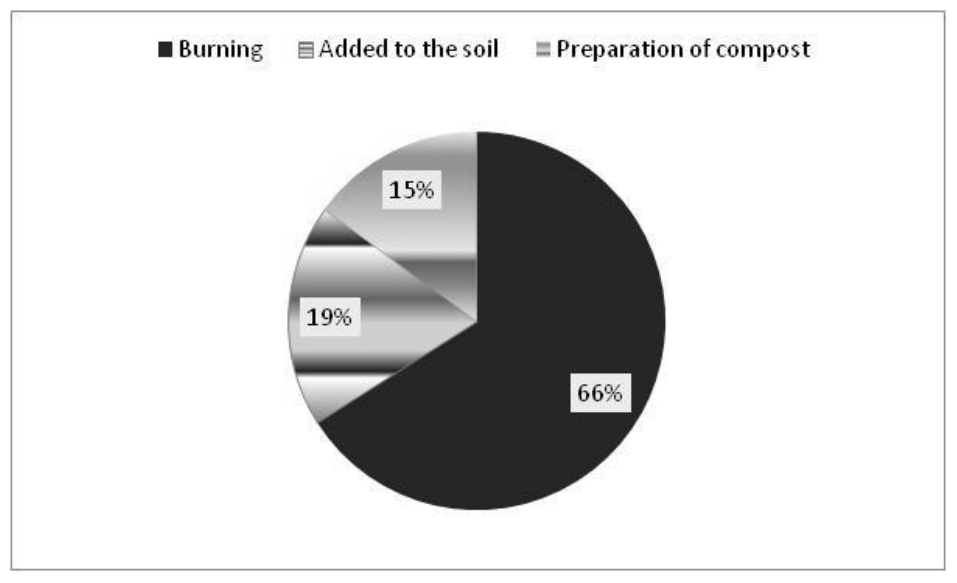

Fig. 5. Purpose of crop residue use in Ludhua village under Noakhali district 
Crop residues important source of soil organic matter which capture soil carbon by the formation of humus. Most of the respondent $86.1 \%$ had concept about crop residue and rest $13.9 \%$ had no concept about crop residue. Among them 66\% respondent used crop residue for burning, $19.1 \%$ respondent added crop residue in the soil and $14.9 \%$ respondent used crop residue for preparation of compost (Fig. 5). Among the farmers most of them (53.2\%) believed that composting increase soil organic matter, $19.1 \%$ believed that cover crops increase soil organic matter, $8.5 \%$ believed that utilization of crop residue increase soil organic matter, $2.1 \%$ believed that reduced tillage increase soil organic matter and rest of the $17.6 \%$ believed that above all practices increase soil organic matter. SALM practices assist in farmers' climate change adaptation processes by increasing the resilience to floods, droughts and erosion through improved water conservation and enriched fertility of soils (Wachiye, 2011).

\section{Conclusion}

So it is clear from the data of the study that climate change occurred and it had direct effect on temperature raising, day-night temperature variation etc. Man made activity mostly responsible for climate change. Conservative agricultural practices such as rotation cropping, conservation tillage and stubble retention, irrigation and fertilization are main drivers for SOC accumulation. Though most of the (57.2\%) farmers had no idea about soil carbon but they followed various soil management practices (crop rotation 90.3\%, irrigation $98.96 \%$ and fertilization $96.8 \%$ ) for better crop production which helps to increase soil organic carbon in the farmer's field.

\section{References}

E Wachiye, 'SCC-ViA and SALM practices' [Interview by Josefin Smeds], Kitale, Kenya, 2011-05-11.
EPA. 2008. Agriculture and Food Supply. http://epa.gov/climatechange/effects /agriculture.html

Luo, Z., Wang, E. and Sun, O.J. 2010. Soil carbon change and its responses to agricultural practices in Australian agro-ecosystems: A review and synthesis. Geoderma, 155: 211123.

Maddison, D. 2006. The perception of and adaptation to climate change in Africa. CEEPA Discussion Paper No. 10. Centre for Environmental Economics and Policy in Africa, University of Pretoria, South Africa. Pp. 47

Paustian, K., Six, J., Elliott, E. T. and Hunt, H. W. 2000. Management options for reducing $\mathrm{CO} 2$ emissions from agricultural soils. Biogeochemistry, 48:147-163.

Rodale Institute. 2008. Regenerative Organic Farming: A Solution to Global Warming. www.rodaleinstitute.org/files/Rodale_Resear ch_Paper-07_30_08.pdf

Sparling, G. P., Wheeler, D., Vesely, E. T. and Schipper, L. A. 2006. What is Soil Organic Matter worth? Journal of Environmental Quality, 35: 548-557.

Wander, M. and Nissen, T. 2004. Value of Soil Organic Carbon in Agricultural Lands. Mitigation and Adaptation Strategies for Global Change, 9, 417-431.

Zhou, Y. Yang, H. Mosler, H-J. and Abbaspour, K.C. 2010. Factors affecting farmers' decisions on fertilizer use: A case study for the Chaobai watershed in Northern China. Consilience: The Journal of Sustainable Development Vol. 4, Iss. 1 Pp. 80-102 